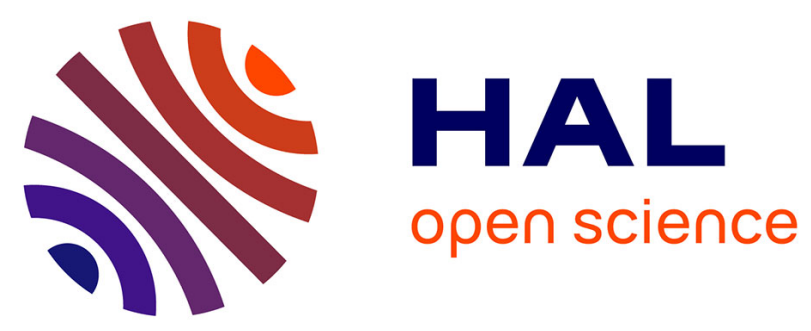

\title{
Development of a Versatile Mechanical Testing Device for In Situ Synchrotron Tomography and Diffraction Experiments
}

Maxime Pelerin, Andrew King, Lucien Laiarinandrasana, Henry Proudhon

\section{- To cite this version:}

Maxime Pelerin, Andrew King, Lucien Laiarinandrasana, Henry Proudhon. Development of a Versatile Mechanical Testing Device for In Situ Synchrotron Tomography and Diffraction Experiments. Integrating Materials and Manufacturing Innovation, 2019, 8 (3), pp.378-387. 10.1007/s40192-01900143-6 . hal-02355866

\section{HAL Id: hal-02355866 https://hal.science/hal-02355866}

Submitted on 12 Oct 2021

HAL is a multi-disciplinary open access archive for the deposit and dissemination of scientific research documents, whether they are published or not. The documents may come from teaching and research institutions in France or abroad, or from public or private research centers.
L'archive ouverte pluridisciplinaire HAL, est destinée au dépôt et à la diffusion de documents scientifiques de niveau recherche, publiés ou non, émanant des établissements d'enseignement et de recherche français ou étrangers, des laboratoires publics ou privés. 


\title{
Development of a Versatile Mechanical Testing Device for In Situ Synchrotron Tomography and Diffraction Experiments
}

\author{
Maxime Pelerin ${ }^{1,2}$ (D) Andrew King ${ }^{2} \cdot$ Lucien Laiarinandrasana $^{1} \cdot$ Henry Proudhon ${ }^{1}$
}

\begin{abstract}
A new mechanical stage to perform in situ 3D imaging using synchrotron X-ray tomography is presented. Pairing control and acquisition allows the running of high quality continuous mechanical tests to study damage and fracture in any kind of structural materials. The modular design make this device very versatile with the possibility to use many specimen geometries and load ranges up to $5 \mathrm{kN}$, and switch within minutes from tomography to X-ray diffraction configurations. Examples of successful experiments to study the damage mechanisms with a technical polymer material are given.
\end{abstract}

Keywords X-ray tomography · Synchrotron experiment · In situ mechanical testing $\cdot$ Structural materials $\cdot$ Automation

\section{Introduction}

In situ 3D imaging has already helped to improve our understanding of damage and failure mechanisms in many kinds of structural materials [1-3]. Synchrotron tomography techniques are maturing, and with an increase in available flux combined with advances in detectors and data acquisition infrastructures, the acquisition time of a tomography measurement has considerably reduced over the years. Measurements that previously required tens of minutes are now routinely performed in tens of seconds, and in many cases, in much less than $1 \mathrm{~s}$. This represents one of the most significant advantages of synchrotron instruments compared with laboratory tomographs [4].

In the field of structural materials, this has significant benefits for the design of in situ mechanical tests. Previously, it was necessary to pause the mechanical test (for example, to hold at a constant applied load or displacement) during the acquisition of each tomogram [4-6], in order to minimize movement or deformation in the

Maxime Pelerin

maxime.pelerin@mines-paristech.fr

1 MINES ParisTech, PSL University, Centre des Matériaux UMR CNRS 7633, BP 87, 91003 Évry, France

2 Synchrotron SOLEIL, L'Orme des Merisiers, BP 48, 91192 Gif-sur-Yvette, France sample which would produce artifacts in the tomographic reconstruction. With shorter acquisition times, interrupted in situ tests can be replaced by continuous tests, since the movements or changes in the sample remain small enough during the measurement time. This brings many advantages. Tests can be performed using conditions that are much closer to those used in standard mechanical testing protocols, ensuring that results are more comparable. In certain materials such as polymers and polymer matrix composites, failure very often occurs during the dwell phase of an interrupted test, and at a much lower applied displacement than in the case of continuous loading. A more extensive series of good quality tomograms throughout the mechanical process of interest provides a more complete description of damage phenomena for materials scientists.

Performing mechanical tests with in situ tomographic inspection for structural materials such as metals, composite materials and polymers, requires a mechanical testing rig that can be installed on a tomography end station. Most synchrotron X-ray micro-tomography beamlines feature an extended parallel beam. The field of view is typically between 0.5 and $5 \mathrm{~mm}$, with a resolution typically in the [0.5-5] $\mu \mathrm{m}$ range. This is often very suitable for the scale of the mechanisms involved in the damage of structural materials. Although local tomography is possible, the field of view generally corresponds to the specimen cross section being tested by in situ mechanical stages. In the past, several devices were produced by various 
research teams and used at many different synchrotron beamlines [7-9]. Based on past experiments and literature review, limits typically appear to be (i) cable management, (ii) automation or synchronization of both control and acquisition, (iii) versatility, and (iv) interrupted tests. This work will showcase a new design addressing all those limits.

These mechanical stages are necessarily significantly modified compared to standard laboratory rigs. Therefore, it is important that they can also be used independently of the tomography setup in order to prepare experiments. This is significant, both to prepare the testing protocols, but also to train the users so that limited experimental time can be used efficiently.

In this paper we present a novel mechanical testing device, nicknamed Bulky, to distinguish it from the much smaller Nanox machine [10]. This has been developed for a range of in situ applications at many different beamlines, as well as ex situ use for experiment preparation. The design constraints and choices are presented in "Technological Description", as well as the main features of the stress rig. Details are given on how the control and acquisition can be advantageously paired and how preliminary tests are carried out before the actual experimental campaigns. Then, experimental results on a technical thermoplastic material in the form of $4 \mathrm{D}$ experiments are described and the main results highlighted in "Experiments". Finally, conclusions and prospects are given.

\section{Technological Description}

\section{Shape and Layout}

It is increasingly the case that tomography instruments are able to accommodate very large samples or in situ sample environments [11]. In some cases, hollow rotation and translation stages even allow equipment or samples to be installed inside the instrument [12]. However, this is not universally the case. Often, the available vertical space between sample stage and the beam is the most important constraint. For example, there is a maximum of $139 \mathrm{~mm}$ below the white beam at the TOMCAT beamline, SLS, Switzerland [13], and $144 \mathrm{~mm}$ available on the highresolution tomography station at the ID19 beamline, ESRF France. Furthermore, the total height of the machine is also a source of many space constraints especially in some configurations: on a multi-circle goniometer or when it is necessary to bring an imaging detector very close to the sample to minimize propagation phase contrast. In order to maximize the adaptability of our machine, it was decided to minimize the distance between the sample and the base of the machine, and to develop a compact design where all the mechanical elements of the machine would be located in the space between the beam plane and the mounting surface on the top plate of the beamline sample stage. As the machine is made of thick steel sections, its total mass is $5 \mathrm{~kg}$; if weight was a critical parameter, it could be reduced by replacing steel with aluminium.

\section{Mechanical}

Microtomography typically uses specimens with a gauge section of a few millimeters square. The mechanical design was made to test specimens up to $5 \mathrm{kN}$ (for high yield strength steels or titanium alloys) and with a mechanical stroke of $15 \mathrm{~mm}$ (for ductile metals and polymers). The overall dimensions and layout of the machine are visible in Fig. 1.

Powertrain A stepper motor was chosen for reasons of precision and ease of control. A reduction gear is used to reduce the minimum step size, increase torque, and to make the load train irreversible. Physically, the motor has 200 steps per turn and the epyciclic gear a 72:1 ratio.
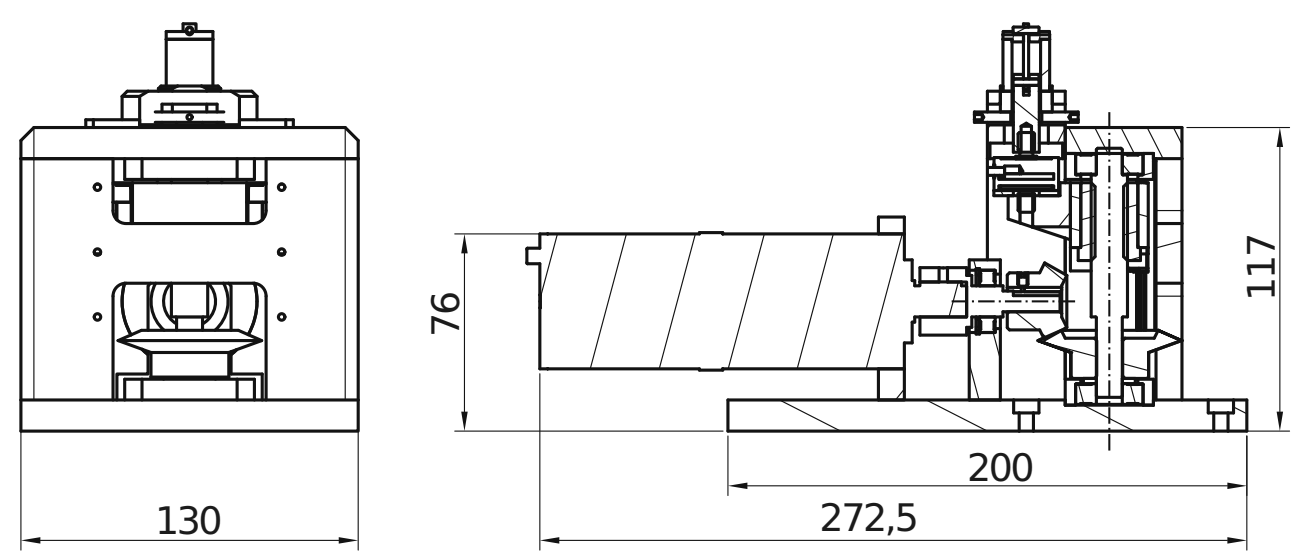

Fig. 1 Front view and cross-section view of the machine in tomography setup 
The motor is fixed horizontally so that it can pass under the head of the X-ray imaging detector when the machine rotates. A bevel gear transmits the rotation of the motor axis to a vertical worm gear while introducing an additional reduction ratio of 2:1. The crosshead of the machine is vertically guided by a pair of linear rails and set in motion through a lead screw with a $3 \mathrm{~mm}$ pitch. The assembly of these different elements is shown schematically on the kinematic diagram in Fig. 2 and the cross-sectional views in Fig. 1. This leads to a total reduction ratio of 9600:1. With a standard stepper motor controller, operating in 1/64 microsteps, the minimum obtainable crosshead speed is $50 \mathrm{~nm} \mathrm{~s}^{-1}$.

A pair of compression springs are symmetrically arranged under the crosshead in order to maintain contact on the same side of the lead screw threads (anti-backlash). This is particularly important for samples tested at low loads. The in-line load cell, is housed within the crosshead. A range of exchangeable load cells from $100 \mathrm{lbs}(445 \mathrm{~N})$ to $1000 \mathrm{lbs}(4.45 \mathrm{kN})$ was purchased from Futek Inc., in order to adapt the precision to the experimental requirements. The lower sample grip is screwed directly to the M6 threaded end of the load cell. A lock nut allows the orientation of the lower grip to be set, and prevents further rotation. The lower grip moves with the crosshead. The upper grip, which is stationary, is fixed on the top of the machine.

This forms the basic body which is common to all experiments. Different assemblies can then be installed for different types of loading and different sample geometries.

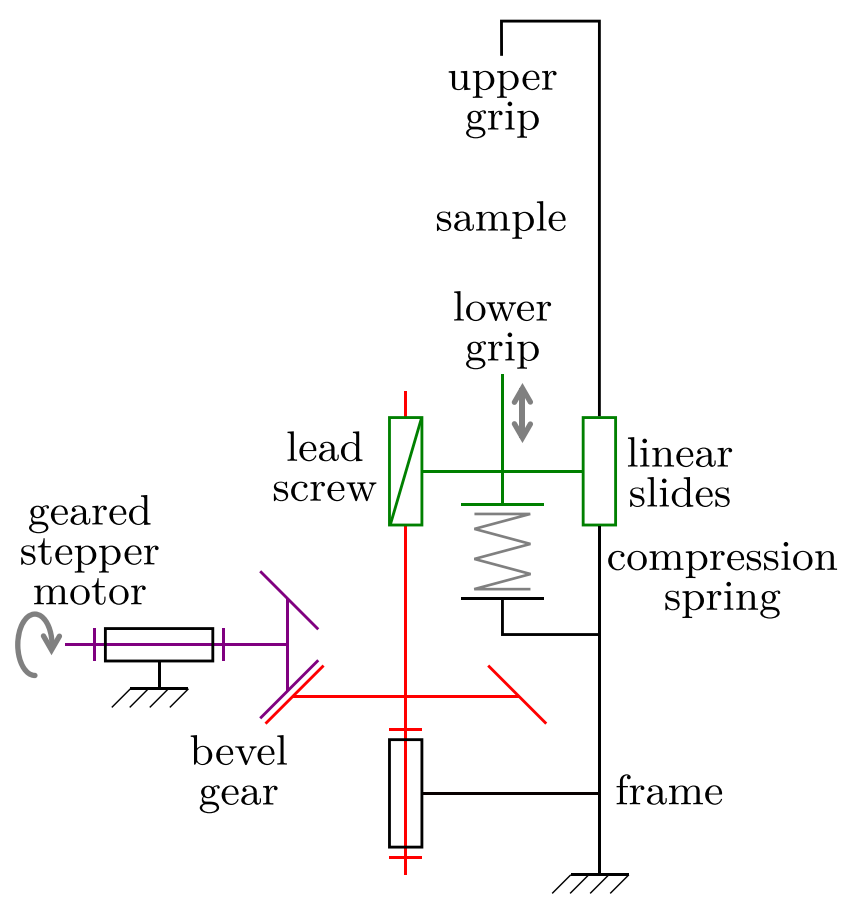

Fig. 2 Labeled minimal kinematic diagram showing the main elements of the powertrain
Some of these are displayed in Fig. 4 and discussed in more detail in part "Versatility" below.

Wiring All the required wiring cables (stepper motor control, conditioner power supply and load measurement, limit switches) are grouped into a single DA-15 connector. In the laboratory, an adaptor cable simply dispatchs the connections to the different hardware. At the synchrotron, this connection passes through a slip ring in order to allow continuous rotation throughout the mechanical test. Note that depending on the actual configuration the number of channels available in the slip ring may limit the number of signals available (a minimum of 8 is required without the limit switches).

Depending of the number of channels available in the beamline slip ring and experimental needs, additional signals (a laser extensometer for instance) can be added.

\section{Control}

TANGO Controls are a free open-source controls toolkit used in many synchrotron sources (ESRF, DESY, ALBA, SOLEIL, ELETTRA, MAX-IV, etc.) [14, 15]. To enable full integration of the mechanical testing machine with the beamline, the choice has been made to control the tensile device using TANGO and compatible hardware. A mobile bay houses all the control electronics and can be moved between the laboratory and the synchrotron.

The system is autonomous and allows a mechanical test to be reproduced under the same conditions in the laboratory and at the synchrotron. For example, it is possible to program a complex loading method and use it to perform preparatory tests in the laboratory (by recording the force/displacement curve, and adding an extensometer and/or optical image acquisition to perform digital image correlation (DIC) or a shadowing method). At the synchrotron, the Tango server is then connected to the beamline control network in slave mode and all the devices declared in its database can be accessed directly from the network. Then, it is possible to properly synchronize the tensile motion, the recorded force signal and any synchrotron measurements: radiography, tomography or diffraction.

TANGO Controls provides full API in $\mathrm{C}++$, Python and Java. Our implementation uses Python which is quite common on beamlines, and is directly compatible with the Python based SOLEIL scripting language SPyC. Motor movements and load cell data acquisition are managed by a small Python script making use of adequate classes from the $x l a b$ library available online [16]. This makes it very simple for the end-user, not necessarily familiar with the inner details of TANGO, to run mechanical tests and to use the same front-end whether in the laboratory or at the synchrotron. For instance, a simple monotonic tensile test 


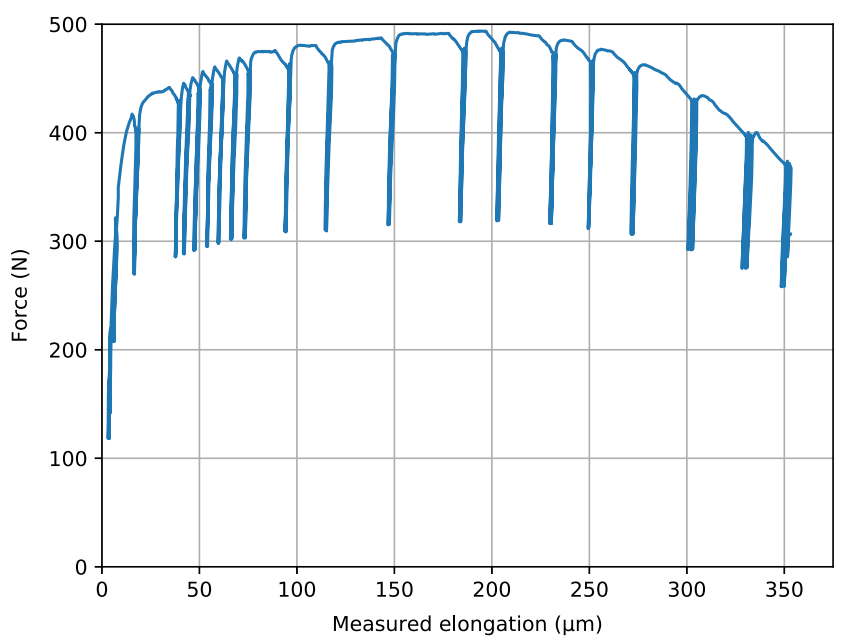

Fig. 3 Compliance test on a pre-cracked steel specimen. At each compliance measurement position, two tomography scans were recorded in the load state and in the unloaded state. A pre-load of more than an hundred Newtons was applied before the test started

with a force/displacement record, could be simply driven by the following lines:

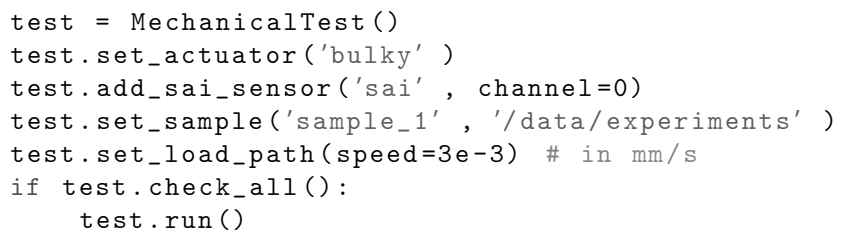

The described hardware/software setup is highly flexible and allows to complete a mechanical test according to specific experimental needs: by adding more sensors or performing more complex loading paths. For instance, for studying crack propagation in steel, an experiment with tensile loading interrupted by several unload/load cycles for measuring the evolution of the compliance (linked to the slope during unload cycles) has been performed (Fig. 3).

As the traction exerted by this machine is asymmetrici.e., the upper grip is stationary and only the lower grip moves - it may be necessary to correct the vertical position of the specimen in order to maintain the minimum cross section in the center of the field of view throughout the mechanical test. Thanks to the control and acquisition pairing, a correction of half of the traction displacement can easily be applied using the vertical translation motor of the tomograph.

\section{Versatility}

This machine is designed to be versatile so as to offer the possibility of testing different specimen geometries suitable for different materials, because it is possible to design dedicated assemblies for specific samples or loading conditions, and because its flexible control allows complex loading paths. A wide range of different assemblies can be installed to adapt the machine to different configurations (see Fig. 4 for selected examples). The machine has already been used with success in a variety of configurations, including:

- polymers and polymer-based composites in situ tomographic studies an different sample geometries [5],

- steel and titanium mechanical testing (loads up to several $\mathrm{kN}$ ),

- tensile on UV irradiated PA films (very low loads $<5 \mathrm{~N}$ ),

- combined diffraction and tomography on PEKK polymers,

- diffraction in situ study of micro-wires [17],

- and more under development: compression, diffraction contrast tomography, etc.

Tomography The loading direction of the mechanical device is vertical and when the machine is mounted on a tomograph, it is adjusted such that the axis of the tomograph is aligned with the center of the specimen. In order to have the widest possible angular aperture and the clearest possible radiographs, a no-pillar design was adopted: the load is transmitted by a tube, rigid enough and with the lowest and most homogeneous X-ray absorption

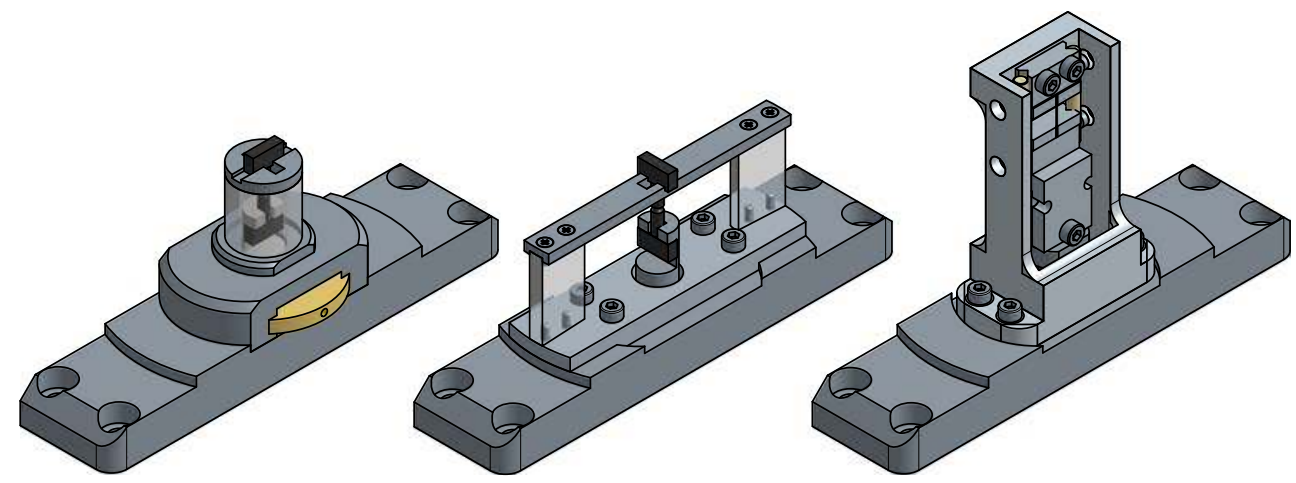

Fig. 4 Different mounting setups: tomography with PMMA tube (left), a diffraction and tomography frame (center), and wire testing setup (right) 
possible. For the room temperature experiments presented in this paper, a PMMA tube is used with an external diameter of $18 \mathrm{~mm}$ and $4 \mathrm{~mm}$ wall thickness. Internal and external surfaces were carefully polished for minimum roughness. Note that the PMMA tube and top-cap assembly is extremely compact to allow the tomography detector to be brought very close to the sample, which is necessary to achieve the highest spatial resolutions in parallel beam tomography (around $10 \mathrm{~mm}$ ) [18]. A minor modification of this design will allow even closer working distances for diffraction contrast tomography [19]; or, thanks to a much longer tube, it might be possible to also use this machine on a laboratory tomograph.

It is this setup which is mounted on the machine in Fig. 1. The outer tube rests on an adjusting screw (in brass color on Fig. 4) allowing adjustment of its effective length for mounting of the specimen or applying a pre-load.

Diffraction Frame For experiments that combine diffraction and tomography on polymeric material, the PMMA outer tube is not suitable since it leads to a strong scattered signal covering the signal from the sample $(2 \times 4-\mathrm{mm}$ PMMA versus typically 2-mm sample material). For these measurements, it was chosen to replace it with a crosspiece supported by two prismatic columns. The columns are also made from PMMA, offering an angular opening of $170^{\circ}$ for diffraction, while remaining partially transparent to the beam, allowing good quality tomography measurements (see "Diffraction" for an example of use).

Wire Testing In collaboration with Institut Pprime [17], a gantry has been designed to host microwires for in situ tensile stress experiments followed by X-ray diffraction. The samples are mounted on a flanged assembly. After mounting and alignment in this gantry, the flanges are removed and the tensile test can be started. Even for the wider nickel micro-wires tested, with a diameter of $100 \mu \mathrm{m}$, the maximum load did not exceed $10 \mathrm{~N}$.

\section{Experiments}

As an example of application of Bulky, we present a series of measurements performed on a high performance polymer material.

\section{Material}

PEKK (Poly-Ether-Ketone-Ketone) [20, 21] is a high performance polymer material. This material is important because it has been developed for use as a polymer matrix in future composite materials in highly demanding areas of application such as aerospace and offshore energy, industries requiring replacements for metallic materials and structures. Such composite materials promise weight savings while maintaining excellent mechanical and industrial properties (lightweight, strength at elevated temperature, formability, and recyclability). Unlike most polymers already used in these fields, PEKK is a thermoplastic and not a thermoset material, which makes it possible to use melt-forming processes such as welding, injection-molding or thermoforming, and to consider its recycling.

The material is used in its semi-crystalline form. The crystalline phase is crucial for maintaining mechanical strength with increasing temperature: The maximum continuous operational temperature is $260{ }^{\circ} \mathrm{C}$ and up to $300{ }^{\circ} \mathrm{C}$ for a short duration. However, the glass transition temperature, corresponding to the shift in mechanical behavior of the amorphous phase from rigid to rubber-like, is about $160{ }^{\circ} \mathrm{C}$. The microstructure consists of thin crystalline lamellae arranged radially around a nucleation point (spheroidal structure) and surrounded by an amorphous phase $[20,22]$. The density difference between the two phases is a very slight number and the stacking scale of these lamellae $(\approx 10 \mathrm{~nm})$ is several orders of magnitude below the resolution observable in micro-tomography ( $\approx 1 \mu \mathrm{m})$.

The samples used in these experimental series were machined from 2-mm-thick injected-molded macroscopic ISO 1BA specimens provided as experimental material by Arkema. Therefore, flat specimen geometries with pin mounting were chosen as shown on Fig. 5. Different geometries of lateral notches create triaxial stress states in the center part of the specimen where the tomography is recorded. The notches with a $1-\mathrm{mm}$ or $10-\mathrm{mm}$ radius were machined by milling. Sharper notches have been obtained by cutting using a pair of razor blades symmetrically
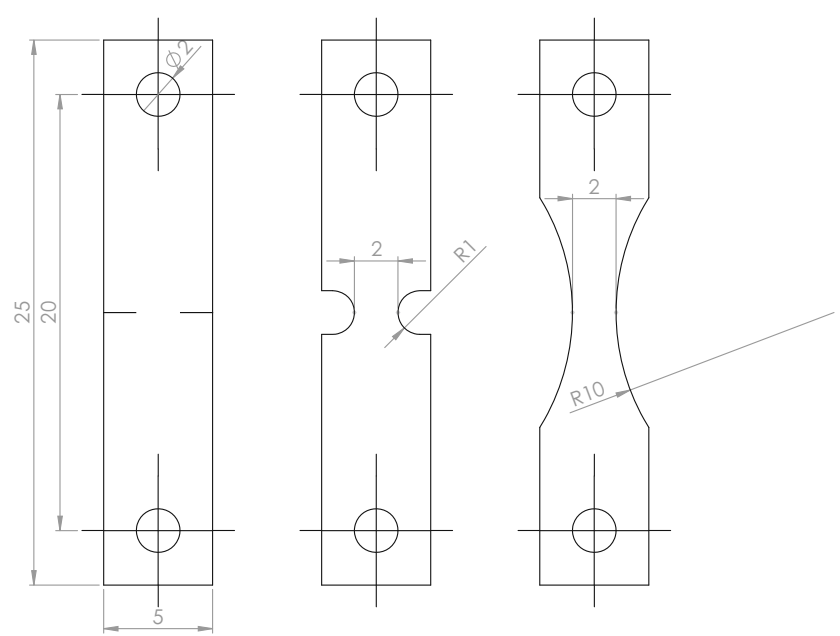

Fig. 5 Examples of typical specimen geometries (the thickness is $2 \mathrm{~mm}$ ) with razor blade notches (left), 1-mm notch radius (center) and $10-\mathrm{mm}$ radius (right) 


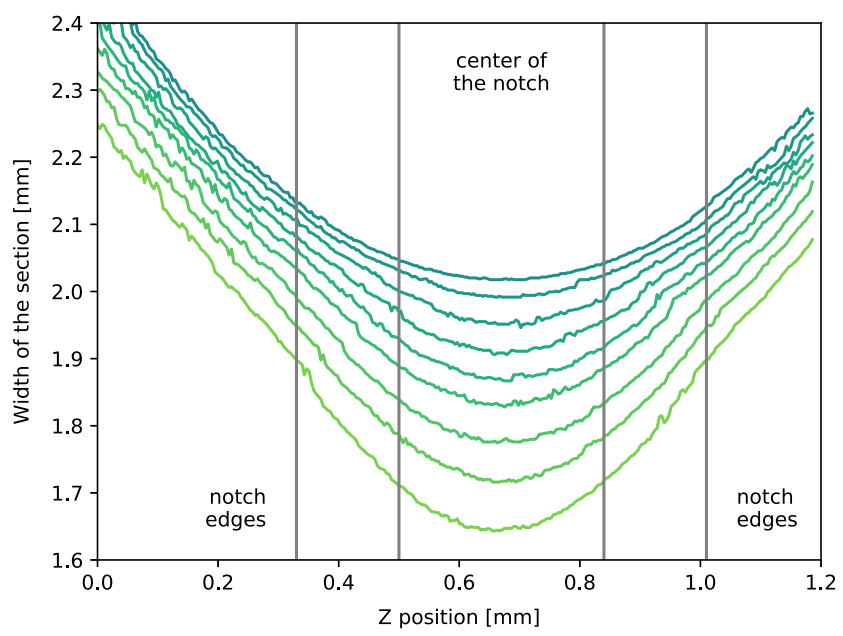

Fig. 6 Evolution of width profiles during the renecking process and definition of the central and outer parts of the notch for radii computation

mounted in a jig, and actuated using a laboratory mechanical testing machine. All geometries depicted in Fig. 5 give an initially square central section of $2 \mathrm{~mm} \times 2 \mathrm{~mm}$. In total, 7 specimens were tested: three specimens with notch radii of $1 \mathrm{~mm}$, two with radii of $10 \mathrm{~mm}$, and two with razor blade notches.

\section{Beamline Setup}

These measurements were made on the PSICHE beamline of the SOLEIL synchrotron, France. This is a hard X-ray beamline using an in-vacuum wiggler source. Tomographic measurements were made in pink beam mode. The beam spectrum was defined using filters including silver foil to exploit the absorption edge at $25.2 \mathrm{keV}$. High-energy photons are rejected by using an $\mathrm{x}$-ray mirror as a low-pass filter.

The radiographic projection of the sample is converted to visible light using a scintillator. A visible light optic forms an image on a camera, giving an effective pixel size of $1.3 \mu \mathrm{m}$ for a field of view $2.6 \mathrm{~mm}$ wide by $1.3 \mathrm{~mm}$ in height [12]. As the absorption contrast is low for a polymeric material at this energy, propagation-based in-line
Fig. 7 Evolution of the geometry of the specimen during the tensile test for a 1-mm notched specimen
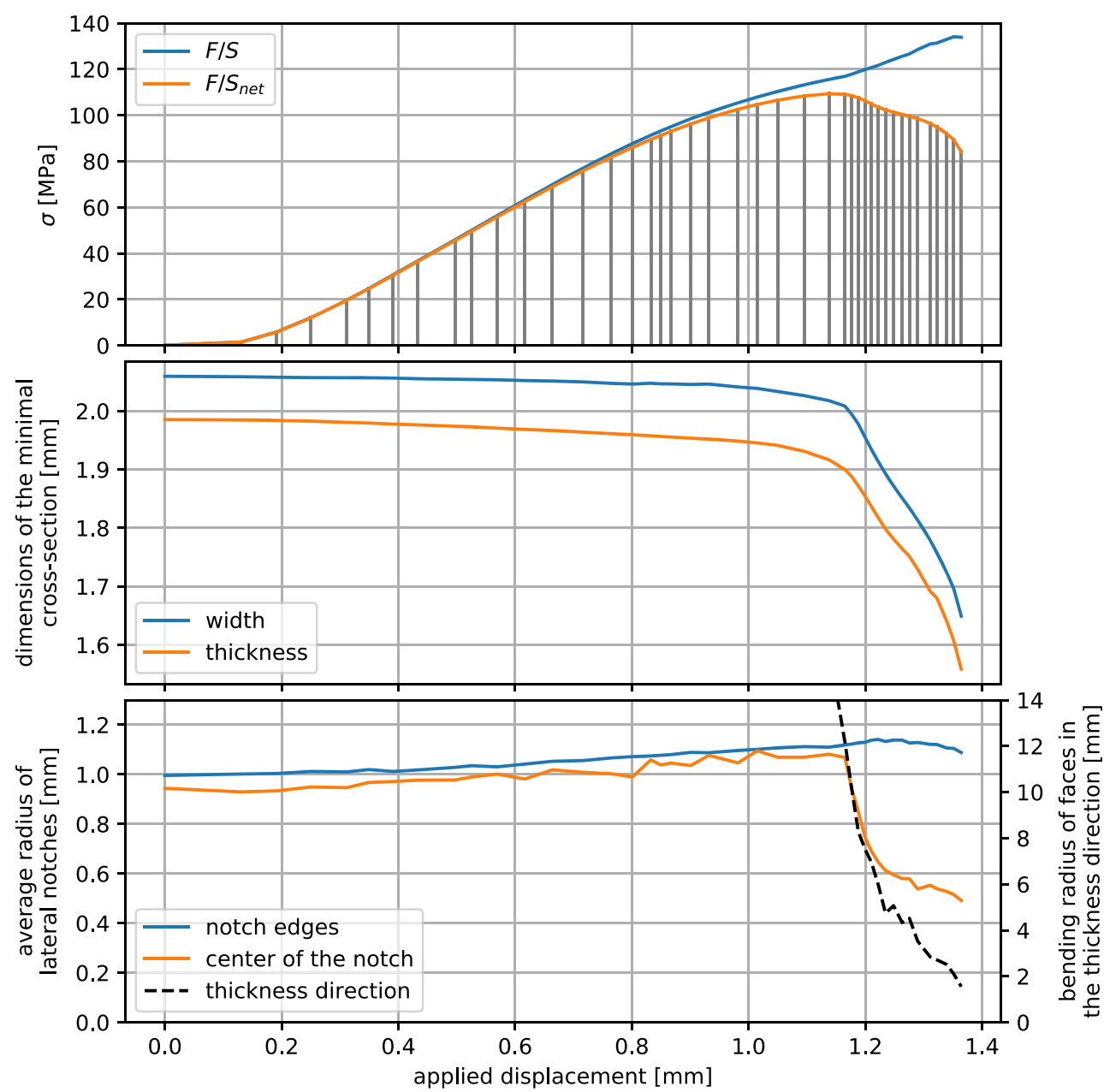

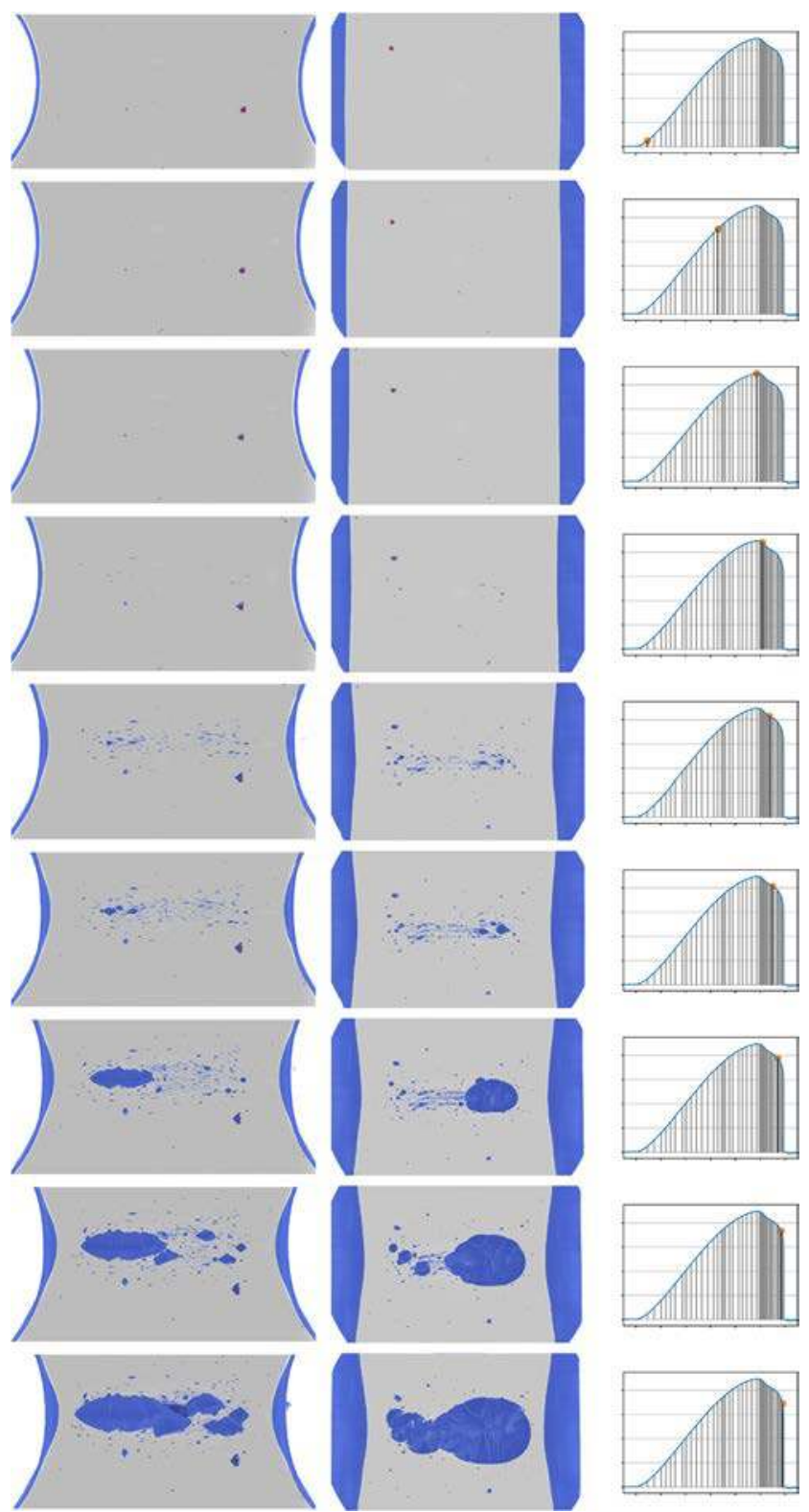

Fig. 8 Qualitative evolution of the microstructure during tensile test. Side view: voids projection on the thickness of the sample (left) top view: projection on the height of the ROI (center) and corresponding position in the loading curve (right), see Fig. 7 for quantitative data

phase contrast and Paganin filtering of the radiographs [23] were used to enhance contrast. The sensor head was placed $65 \mathrm{~mm}$ from the observed area in order to get a good compromise in terms of phase contrast.

In addition, the Wide-Angle X-ray Diffraction (WAXS) results presented in part "Diffraction" were obtained in monochromatic mode. A monochromator, with two Si (111) crystals in Bragg-Bragg geometry, has been adjusted to have a beam with an energy of $25 \mathrm{keV}$ [24]. This mode can also be used to perform tomography (although at a much slower rate).

\section{In Situ Tomography Loading and Measurement}

A tensile test was carried out with a continuous increasing traction displacement at a crosshead speed of $0.4 \mu \mathrm{m} \mathrm{s}^{-1}$. Since the elongation before breaking is much greater than the height of the field of view, the automated height correction described in part "Control" was applied. As the vertical translation of the tomograph cannot achieve continuous movement at such a low speed, this correction is performed in jerks, carefully avoiding acquisition times thanks to the acquisition/control pairing.

Tomography acquisitions consist of the recording of a thousand radiographs equally distributed over a half turn and require a total of 6 seconds. Here, only half of the detector height was used in order to speed up the acquisition. It is also possible to take a reference image of the beam, for further flat-field correction of radiographs, by sweeping the sample away and calculating the average over a small time series of images. To move the PMMA outer tube completely out of sight, it is necessary to move sideways by $15 \mathrm{~mm}$, which makes the operation relatively time-consuming: 20 seconds are necessary to remove the entire tube from the field of view, image the beam, and reposition the sample.

A Python script, running in a beamline control terminal, automatically executes the progress of a mechanical test:

- it coordinates all motor movements (tensile loading, vertical compensation, displacements for measurements),

- it acquires, saves, and displays the various relevant signals (tensile displacement, load cell force, etc.),

- it manages the triggering of tomography measurements at regular intervals,

- $\quad$ and it stops when the sample breaks.

Tomograms can be recorded at constant time intervals or, in the present case of highly non-linear material response, the acquisition frequency can be controlled directly by the user. This allows for more data acquisition in the vicinity of an interesting transition and by triggering the taking of a reference image when the beam has slightly drifted and the previous one becomes inadequate. Mechanical tensile tests presented here typically lasted 20 min with 25 to 50 tomography images recorded.

\section{Results}

Preprocessing: 3D Volume Registration Indeed, the motion of the specimen during the test and angular fluctuations related to the jitter when starting an acquisition in this rapid tomography mode, create a rigid body motion which is combined with the actual deformation of the material in the reconstructed volume of interest. This needs to be corrected to track the evolution of damage throughout 


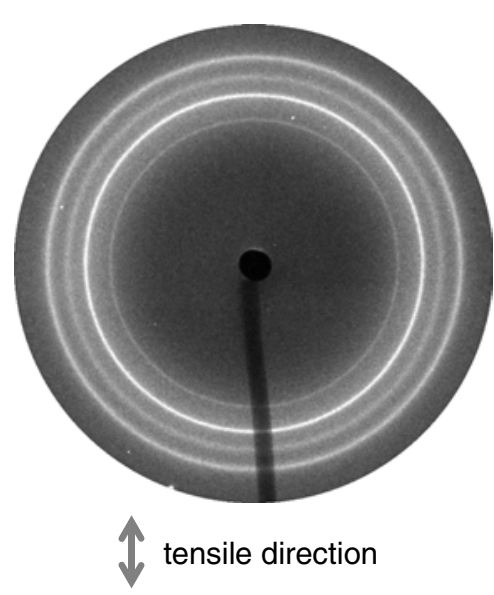

(a)

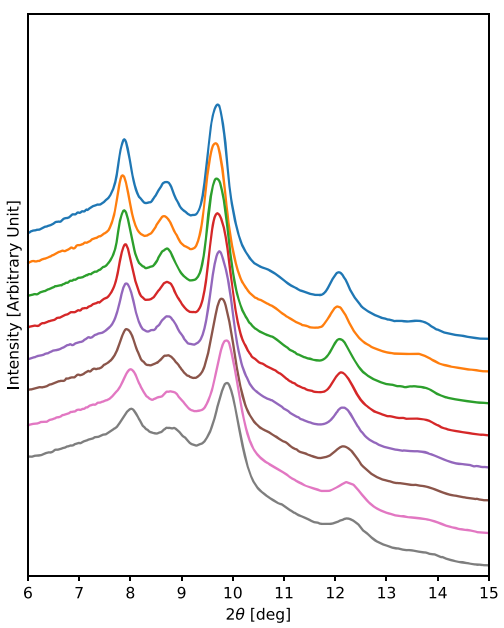

(b)

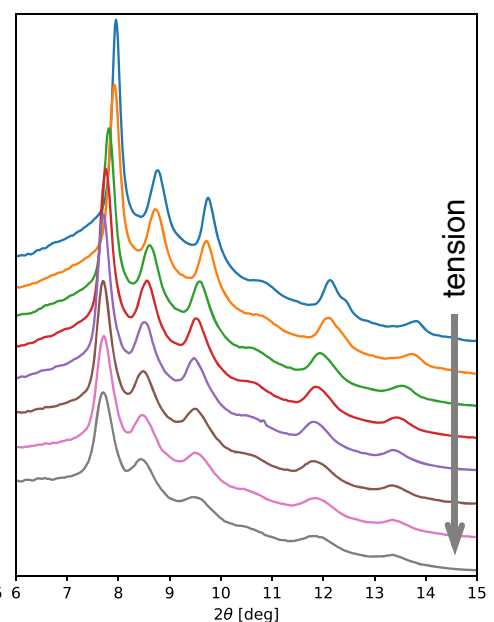

(c)

Fig. 9 An initial diffraction pattern (a) and the evolution of diffracted intensity during a tensile test in two directions: perpendicular (b) and parallel (c) to the tensile direction (the lowest curves correspond to the most advanced tensile state)

the mechanical test. With the data collected, a method to register spatially (determine the 6 degrees of freedom of the rigid body motion) was developed. The method is based on the detection of faces in the sinograms. As this is carried out without reconstruction, this method is fast enough $(\approx 6 \mathrm{~s} \mathrm{per}$ tomogram using a single core of an ordinary workstation) to consider real-time processing as the experiment progresses. However, it is limited in its current form to samples of quadrilateral straight sections with at least a portion of the different faces within the field of view.

From the pre-calculated information, the complete volumes are reconstructed by correcting an angular offset (a fluctuation of $\pm 1^{\circ}$ around the main rotation of the tomograph was measured) and by performing a rectangular parallele-piped cropping as close as possible to the useful area in order to limit the size of the series of reconstructed volumes. This provides a complete, registered, $4 \mathrm{D}$ data set of the corresponding mechanical test.

Macroscopic Data The method described above also provides access to the evolution of geometric parameters of the sample: lateral and through thickness contraction, radii of the notch and during necking (Figs. 6 and 7). Calculating these parameters in real time during the mechanical test is useful as a decision-making aid or as a rapid analysis tool for comparing different specimens.

For instance with a 1-mm notched sample, Fig. 7 shows the engineering stress defined as the force divided by the initial section $\left(S_{n e t}\right)$ plotted as a function of the applied displacement. Each vertical gray line represents a tomographic scan. During the test, the notch is first blunted: the initial $1 \mathrm{~mm}$ radius increases and there is a slight contraction of both width and thickness. From the peak of maximum stress, necking in the thickness is observedthe dotted line represents the average radius of curvature of the two initially flat surfaces of the specimen (at the beginning of the test, the radius is therefore infinite) and the scale is on the right axis-and renecking [25, 26] of the lateral notches-the orange line represents the radius computed only with a $300-\mu$ m-high ROI centered on the minimum cross section and the blue line represents the radius computed from the border of the notches (cf. Fig. 6).

On 10-mm radius notched specimens, necking occurs, propagating up to the limit of the machine stroke or leading to a rupture initiated on the surface of the sample. For specimens with a much smaller radius-razor blade notches - the failure occurred suddenly and the loading curve did not show any softening.

Microscopic Data The 3D analysis of the reconstructed volumes makes it possible to visualize the damage mechanisms: nucleation, growth and coalescence of voids on the PEKK for this notch radius of $1 \mathrm{~mm}$. The appearance of the first cavities is at a distance from the bottom of the notch (Fig. 8).

On the top views (middle column), the warping of the notch bottom section can be observed (the other two sides are outside the field of view and thus not visible). On the side views (right column), the renecking that was measured in Fig. 7 is visible. 
Such data on the final steps provide a better understanding of how the failure occurred and the fracture surface was formed.

\section{Diffraction}

During a tensile test with the diffraction frame presented in part "Versatility", several WAXS patterns were recorded throughout the deforming process showing that the crystalline phase undergoes microstructural changes during the mechanical test. In particular, in Fig. 9, the spectra show a different peak shift depending on the directions: axial in the loading direction or transverse perpendicular to the axial direction. The shape of the peaks widens. These changes in the WAXS patterns were attributed to a heterogeneous strain state within the semi-crystalline microstructure [27, 28]. Future works aim at analyzing these simultaneous strains at the scale of the crystallites (XRD) and the void evolution (as obtained by X-ray tomography). The multi-modal characterization will allow a better understanding of the distribution of the stress within the semi-crystalline microstructure.

\section{Conclusion}

A new compact design for testing with a wide range of materials and microstructures for multi-modal studies was presented. 4D experiments are increasingly used for identifying mechanical behavior models with a 3D-based method, using deformations of the specimens, marker networks in the microstructure, etc. This makes it possible to visualize and quantify the damage mechanisms and in particular their kinetics during these tests, which are resolved in time.

The versatility and flexibility of the machine's very open architecture, both from a hardware and a software point of view, allow complex tests to be performed to meet specific experimental needs. As the assembly is designed in a modular way, it is easy to design and machine a dedicated assembly or to program a specific protocol. As shown by the experiments presented on the PEKK material, it is also feasible to advantageously combine different measures in order to carry out increasingly rich and multi-modal tests to give access to simultaneous evolution of different variables or to compare different techniques during the same test and allow further interpretation.

Acknowledgments We would like to acknowledge SOLEIL synchrotron for beam time allocation 20170058 and 20180689 and Arkema for providing the samples material. Yann Auriac (Centre des Matériaux) is acknowledged for helping to design the machine.

\section{Compliance with Ethical Standards}

Conflict of Interest The authors declare that there is no conflict of interest.

\section{References}

1. Buffière JY, Proudhon H, Ferrié E, Ludwig W, Maire E, Cloetens $P$ (2005) Three dimensional imaging of damage in structural materials using high resolution micro-tomography. Nucl Inst Methods Phys Res B: Beam Interactions with Materials and Atoms 238(1-4):75. https://doi.org/10.1016/j.nimb.2005.06.021

2. Scott A, Mavrogordato M, Wright P, Sinclair I, Spearing S (2011) In situ fibre fracture measurement in carbon-epoxy laminates using high resolution computed tomography. Combust Sci Technol 71(12):1471. https://doi.org/10.1016/j.compscitech.2011. 06.004

3. Withers P, Preuss M (2012) Fatigue and damage in structural materials studied by X-ray tomography. Annu Rev Mater Res 42(1):81. https://doi.org/10.1146/annurev-matsci-070511-155111

4. Maire E, Withers P (2014) Quantitative X-ray tomography. Int Mater Rev 59(1):1. https://doi.org/10.1179/1743280413Y. 0000000023

5. Poulet PA, Hochstetter G, King A, Proudhon H, Joannès S, Laiarinandrasana L (2016) Observations by in-situ X-ray synchrotron computed tomography of the microstructural evolution of semicrystalline Polyamide 11 during deformation. Polym Test 56:245. https://doi.org/10.1016/j.polymertesting.2016.10.023. http:// www.sciencedirect.com/science/article/pii/S0142941816309217

6. Löffl C, Saage H, Göken M (2019) In situ X-ray tomography investigation of the crack formation in an intermetallic betastabilized TiAl-alloy during a stepwise tensile loading. Int $\mathrm{J}$ Fatigue 124:138. https://doi.org/10.1016/j.ijfatigue.2019.02.035

7. Buffière JY, Maire E, Adrien J, Masse JP, Boller E (2010) In situ experiments with $\mathrm{X}$ ray tomography: an attractive tool for experimental mechanics. Exp Mech 50(3):289

8. Schuren JC, Shade PA, Bernier JV, Li SF, Blank B, Lind J, Kenesei P, Lienert U, Suter RM, Turner TJ, Dimiduk DM, Almer J (2015) New opportunities for quantitative tracking of polycrystal responses in three dimensions. Curr Opin Solid State Mater Sci 19(4):235. https://doi.org/10.1016/j.cossms.2014.11.003

9. Dezecot S, Maurel V, Buffiere JY, Szmytka F, Koster A (2017) 3D characterization and modeling of low cycle fatigue damage mechanisms at high temperature in a cast aluminum alloy. Acta Mater 123:24. https://doi.org/10.1016/j.actamat.2016.10.028

10. Gueninchault N, Proudhon H, Ludwig W (2016) Nanox: a miniature mechanical stress rig designed for near-field X-ray diffraction imaging techniques. J Synchrotron Radiat 23(6):1474. https://doi.org/10.1107/S1600577516013850

11. Renier M, Bernard P, de Vijver WV, Smets K, Tafforeau P (2013) A large size sample stage for high resolution 2D and 3-D X-ray imaging. J Phys Conf Ser 425(21):212008. https://doi.org/10.1088/1742-6596/425/21/212008

12. King A, Guignot N, Zerbino $\mathrm{P}$, Boulard E, Desjardins $\mathrm{K}$, Bordessoule M, Leclerq N, Le S, Renaud G, Cerato M, Bornert M, Lenoir N, Delzon S, Perrillat JP, Legodec Y, Itié JP (2016) Tomography and imaging at the PSICHE beam line of the SOLEIL synchrotron. Rev Sci Instrum 87(9):093704. https://doi.org/10. $1063 / 1.4961365$ 
13. SLS TOMCAT X02DA beamline team (2019) Sample holder specs for users. https://www.psi.ch/sites/default/files/import/sls/ tomcat/Station1_IntroEN/sample_holder_specs2017_v2.pdf

14. Chaize JM, Götz A, Klotz WD, Meyer J, Perez M, Taurel E (2019) TANGO-an object oriented control system based on CORBA

15. The Tango Community (2019) TANGO controls. https://www. tango-controls.org/

16. Pelerin M, Proudhon H (2019) xlab, Sets of programs and commands to control in situ mechanical experiments. https:// github.com/heprom/xlab

17. Purushottam Raj Purohit R, Arya A, Bojjawar G, Pelerin M, Van Petegem S, Proudhon H, Mukherjee S, Gerard C, Signor L, Mocuta C, Casati N, Suwas S, Chokshi AH, Thilly L (2019) Revealing the role of microstructure architecture on strength and ductility of Ni microwires by in-situ synchrotron X-ray diffraction. Sci Rep 9(79). https://doi.org/10.1038/s41598-018-36472-3

18. Weitkamp T, Haas D, Wegrzynek D, Rack A (2011) ANKAphase: software for single-distance phase retrieval from inline X-ray phase-contrast radiographs. J Synchrotron Radiat 18(4):617. https://doi.org/10.1107/S0909049511002895. https:// onlinelibrary.wiley.com/doi/abs/10.1107/S0909049511002895

19. Johnson G, King A, Honnicke MG, Marrow J, Ludwig W (2008) $\mathrm{X}$-ray diffraction contrast tomography: a novel technique for three-dimensional grain mapping of polycrystals. II. The combined case. J Appl Crystallogr 41(2):310. https://doi.org/10.1107/ S0021889808001726

20. Gardner KH, Hsiao B, Matheson RR, Wood B (1992) Structure, crystallization and morphology of poly (aryl ether ketone ketone). Polymer 33(12):2483. https://doi.org/10.1016/0032-3861(92) 91128-O. http://www.sciencedirect.com/science/article/pii/00323 86192911280

21. Hsiao B, Chang IY, Sauer BB (1991) Isothermal crystallization kinetics of poly(ether ketone ketone) and its carbon-fibrereinforced composites. Polymer 32(15):2799. https://doi.org/10. 1016/0032-3861(91)90111-U. http://www.sciencedirect.com/scie nce/article/pii/003238619190111U

22. Verma R, Kander R, Hsiao B, Wood B (1994) A study of the damage accumulation process in poly(aryl ether ketone ketone) and its AS4 carbon fiber reinforced compos- ites. 1. Mechanical properties. Sci Eng Compos Mater 3. https://doi.org/10.1515/SECM.1994.3.4.227

23. Paganin D, Mayo SC, Gureyev TE, Miller PR, Wilkins SW (2002) Simultaneous phase and amplitude extraction from a single defocused image of a homogeneous object. J Microsc 206(1):33. https://doi.org/10.1046/j.1365-2818.2002.01010.x. https://online library.wiley.com/doi/abs/10.1046/j.1365-2818.2002.01010.x

24. King A, Guignot N, Deslandes JP, Pelerin M, Joosten I, Looff DD, Li J, Bertrand L, Rosenberg E, Dewaele A, Boulard E, Godec YL, Perrilat JP, Giovenco E, Morard G, Weitkamp T, Scheel M, Perrin J, Chevreau H, Itié JP (2019) Recent imaging developments at the PSICHE beamline, Integrating Mater Manuf Innov submitted

25. Challier M, Besson J, Laiarinandrasana L, Piques R (2006) Damage and fracture of polyvinylidene fluoride (PVDF) at $20{ }^{\circ} \mathrm{C}$ : Experiments and modelling. Eng Fract Mech 73(1):79. https://doi.org/10.1016/j.engfracmech.2005.06.007. http://www. sciencedirect.com/science/article/pii/S0013794405001761

26. Boisot G, Laiarinandrasana L, Besson J, Fond C, Hochstetter G (2011) Experimental investigations and modeling of volume change induced by void growth in polyamide 11. Int $\mathbf{J}$ Solids Struct 48(19):2642. https://doi.org/10.1016/j.ijsolstr.2011.05.016. http://www.sciencedirect.com/science/article/pii/ S0020768311001880

27. Xiong B, Lame O, Chenal JM, Men Y, Seguela R, Vigier G (2017) Critical stress and thermal activation of crystal plasticity in polyethylene: influence of crystal microstructure and chain topology. Polymer 118:192. https://doi.org/10.1016/j.polymer.2017. 05.011. http://www.sciencedirect.com/science/article/pii/S003238 6117304780

28. Xiong B, Lame O, Seguela R, Men Y (2018) Micro/macrostress relationship and local stress distribution in polyethylene spherulites upon uniaxial stretching in the small strain domain. Polymer 140:215. https://doi.org/10.1016/j.polymer.2018.02.052. http://www.sciencedirect.com/science/article/pii/ S0032386118301770 